\title{
Collective Action in Common Pool Resource Management, Including Heterogeneity of Opportunities and Exit Options
}

\author{
Pilar Useche \\ Department of Food and Resource Economics \& Center for Latin American Studies, University of Florida, Gainesville, USA. \\ Email: useche@ufl.edu
}

Received September $18^{\text {th }}, 2013$; revised November $17^{\text {th }}, 2013$; accepted November $30^{\text {th }}, 2013$

Copyright (C 2013 Pilar Useche. This is an open access article distributed under the Creative Commons Attribution License, which permits unrestricted use, distribution, and reproduction in any medium, provided the original work is properly cited. In accordance of the Creative Commons Attribution License all Copyrights (C) 2013 are reserved for SCIRP and the owner of the intellectual property Pilar Useche. All Copyright (C 2013 are guarded by law and by SCIRP as a guardian.

\begin{abstract}
The mechanism through which exit options and outside opportunities affect cooperation outcomes has not been well studied in the resource management literature, since a deep analysis of the concepts of "exit options" and "outside opportunities” is missing. This article analyzes these concepts across the common pool resource management literature, investigates the factors that underlie "opting out" decisions, and reviews potential ways to operationalize these concepts for empirical analysis. It also explores how the relationship of cooperation and exit options may be influenced by broad economic processes, such as economic integration.
\end{abstract}

Keywords: Natural Resource Management; Collective Action; Common Pool Resources; Environmental Economics; Economic Development

\section{Introduction}

Since Olson's [1] controversial results about the logic of collective action, the literature examining cooperation behavior in common pool resource management has been trying to disentangle the role of wealth inequality in promoting or obstructing successful collective action across a group of agents. Recently, some authors argued that it is not inequality of wealth per se that matters for participation and agreement, but rather inequality of wealth relative to available opportunity costs and exit options that individuals have to exit a specific collective action situation [2]. For instance, if individuals obtaining a vital resource from a particular source have no alternative provision sources, then the degree of wealth inequality may not alter cooperation outcomes.

In common pool resources worldwide, however, many players have opportunities to move extractive activities elsewhere, which may reduce their interest or concerns about the conservation of the resources in a given locality. Some authors have found that larger and wealthier resource users have more outside opportunities than smaller ones. The latter have been regarded as being more invested in the long-term viability of local resources. This has been noted in the case of Mali and Mauritania, where large and usually absentee livestock herd owners have shown little interest in local arrangements for rangeland management to prevent overgrazing and desertification [3]. Similarly, in Texas shrimp fisheries, Johnson and Libecap [4] have found that larger fishers have defected from quota schemes. However, the relative value of exit options can also be influenced by other factors. For example, mobile populations of poor refugees or immigrants may be more prone to use destructive extractive techniques in common pool resources $[5,6]$.

The mechanism through which exit options and outside opportunities affect cooperation outcomes has not been well studied in the literature and a deep analysis of the concepts themselves is missing in the literature. This article analyzes the notions of "exit options" and "heterogeneity of opportunities" across the common pool resource (CPR) management literature, investigates the factors that underlie "opting out" decisions, and reviews potential ways to operationalize these concepts for empirical analysis. It also explores how the relationship of cooperation and exit options may be influenced by broad economic processes, such as market integration.

In what follows, first, some theoretical approaches to the topic of inequality of opportunities as seen by the 
CPR management literature are discussed. Second, explanations are provided on how the exit options are regarded in empirical studies in this literature, and suggestions are made for broadening the examination of the concept beyond the standard micro-level analysis of wealth inequality. Finally, a summary of conclusions is derived from the discussion.

\section{Exit Options, Opportunity Cost Heterogeneity, and Wealth}

The topic of alternative (exit) options and the heterogeneity in opportunity costs of participation in collective action has been mentioned in many studies as an important determinant of the cooperation or non-cooperation of agents, but only in a few has it been rigorously analyzed. In most models analyzing the provision of common pool resources, the wealth of the individuals usually enters the model only as a direct mapping from income to the capacity deployed to extract a resource [7-10] or to the interest/benefit derived from contributing to the public good. Alternative wealth or resource provision sources are often omitted in conceptual models and opportunity costs of participation are often considered constant across agents (e.g., Ostrom and Gardner study irrigation systems assuming away this type of inequality, while focusing on locational asymmetries with respect to the water source) [11].

As explained by Baland and Platteau [8], the marginal cost of effort or cooperation is likely not constant across individuals, instead it may depend on the opportunity cost of time and wealth of each person. For example, different rates of time preference of CPR users might reflect the existence of different outside economic opportunities that bear some relation to wealth. This is an important aspect to take into account when analyzing collective action and cooperation in the provision and management of CPRs, since it provides an explanation for cooperation that diverges from the standard logic of individual actors assessing participation purely based on absolute values of extraction benefits, and acknowledges some subjectivity or contextual influence in the outcomes. For example, heterogeneity in socio-economic factors, such as education, which in turn have an influence on the opportunity cost of time, may influence collective action outcomes.

The rate of time preference of an individual "i” with wealth level " $X_{\mathrm{i}}$ " over a CPR can be modeled as the factor: $X_{\mathrm{i}} / \Sigma X_{\mathrm{j}}$, where $\Sigma X_{\mathrm{j}}$ is the sum of the wealth of all members participating in the provision or extraction of the resource. This type of representation implies a oneto-one relationship between the relative wealth position in the group of the individual and his/her outside opportunities. An analogous result for education could be obtained if the rate of time preference of an individual de- pended on his/her education level, rather than on wealth. This is a simple way in which heterogeneous time preferences can be operationalized in empirical models, bringing much richer insight to the analysis of collective action $[8,9]$.

Opportunity costs of participation may also depend on whether needed contributions to CPR provision or management are monetary or time based. Baland and Platteau $[8,9]$ show that when opportunity costs of time are increasing in the amount of (time) voluntary contributions to CPR management, "richer agents contribute less to the common good if the opportunity cost of their time is very sensitive to their own wealth." To the contrary, with monetary contributions, their results show contributions increasing more than proportionately with income.

The latter point of inquiry by Baland and Platteau constitutes an important step forward in a literature that is used to deal with constant marginal costs of time. However, this type of heterogeneity lacks the analysis of the different results that can be achieved if individuals are allowed to have different opportunity costs of time and to exit collective action once this opportunity values are high enough relative to their actual activity values. This extension is analyzed by Dayton-Johnson and Bardhan [7] and is discussed below.

Dayton-Johnson and Bardhan model the relation between wealth and cooperation by characterizing the value of exiting from a cooperation setting as a function that is increasing in wealth, and they allow this relationship to be either concave or convex. They highlight the importance of the "shape" of the exit function in terms of the ability to predict cooperation equilibria in their fishery setting. In particular, if this shape is convex, increases in wealth will increase the value of exiting at an increasing rate, providing for an explanation of situations where the richest individuals have very little incentives to cooperate. In the case of a concave relationship where increases in wealth increase the value of exiting at a decreasing rate, achieving cooperation outcomes in unequal wealth settings is likely once the outcome value reaches a specific threshold.

In the case where the exit option function is the same for all individuals and is concave in the endowments, there are two important equilibrium results. First, if full conservation (cooperation) is an equilibrium outcome under perfect equality, then there is always some more unequal distribution of endowments under which full conservation cannot be achieved. In this case, extreme inequality may possibly enhance the prospects of conservation (by assigning enough wealth to one or a few individuals willing and able to provide the public good). Second, the poor have more incentive to exit. This finding contradicts many case studies suggesting that it is the rich members who tend to exit due to their better alterna- 
tive opportunities. Such a situation, where the poor are more likely to not cooperate, has been described in southern Burkina Faso by Laurent, Mathieu, and Totte [5], where poor immigrants are more prone to use destructive gathering techniques in communal forests. However, lack of interest in cooperation by the poor in extremely unequal situations may also be associated with relative opportunity cost of long-term investments in conservation with respect to the urgent needs for their families' survival [12]. The idea that highly mobile individuals may be less interested in long-term action, for example, natural-resource conservation, is discussed below in further detail.

A convex exit function seems more appropriate where there are increasing returns to endowments in the value of the exit-option function. In this case, the richest sections of the population have the greatest incentives to exit (the poorest will also have increased incentives if convexity is related to initial fixed costs). This contradicts to a certain degree Olson's [1] seminal hypothesis that the larger player has the greatest interest in collective action. Indeed, in this convex case, when the poor expect that their counterparts will cooperate, they will have additional and more than proportional incentives not to exit. This outcome has been found in the case of the provision of water in Chad and Kashmir [13] and it has been termed the middle-class participation effect. In the Ghanaian Volta Basin, however, Engel, Iskandarani, and Useche [14] find the exact opposite result: poor and rich are more likely to participate. In this case, the authors argue that participation of the poor may be demanddriven and not so much related to their opportunity cost of time since the program implementers specifically targeted the poor with incentives, such as free meals, and the time invested in participation is low. One could also expect in the case of local water provision that the value of exiting should not present increasing returns since the rich will benefit more if the water is provided locally, rather than in another location. So convexity would not be the most appropriate representation of the exit option value.

Another perspective provided by Dayton-Johnson and Bardhan's conceptualization of the exit option function [7] is that both the level of wealth inequality and the range of income of all participants matter. In a scenario where individuals have exit options, full conservation cannot be an equilibrium outcome under perfect equality if average wealth is below some threshold level. But even when average wealth exceeds the critical threshold, Dayton-Johnson and Bardhan find that further increases in inequality (seen as mean-preserving spreads of the wealth distribution) will reduce some individuals' wealth to the point where their claim on the resource stock may provide insufficient incentives to participate in its provi- sion/management, especially if there are fixed costs associated with this provision. Thus, inequality makes full cooperation more difficult in that case. As the wealth distribution becomes even more unequal, participation may become attractive for the wealthier individual, who can cover fixed costs and obtain some type of monopoly rights over the resource.

\section{Another Perspective on Outside Options: Migration}

Several case studies (Johnson and Bardhan 2002) of fisheries, rangeland, and forest management have pointed out that large agents (companies, fishers, industrial seiners, livestock herd owners, national entities, etc.) are less concerned about local commitment to conservation of resources because they have more opportunities than do small agents to move elsewhere to continue their production activities. Other authors highlight the fact that poor agents also exercise exit options. In particular, when they migrate from other regions, are landless, and/or are interested in extracting some resource for a rapidly growing market [5,6,8]. Pichon [15] describes agricultural colonists in the Amazonia as "highly mobile, speculative, and uninterested in long-term natural resource development.”

Baland et al. [10] argue that the rich tend to have better access to external financial, human, and social capital. The poor, however, look for outside employment to improve their financial income. Outside opportunities often require the migration of family members out of the village, and Baland and Platteau (1999, p. 775) suggest that while the poor tend to keep the links to their villages "to protect the CPR," rich migrants tend to cut off their ties with the native village. This point is worth analyzing further, since it suggests not only the importance of economic stratification, but also the way in which individuals are linked with each other and with their environment.

Dimensions of the individuals other than wealth are little analyzed in the context of "exit options": the type of links to the local space, their mobility, or the speculative character of their production activities tend to be neglected. As an example, migration can be regarded as either "exiting" or not, depending on its temporal or spatial character. Also, the strength of local social networks is not only a key factor determining the types of links of migrants to their place of origin, but is also generally regarded as an important factor enabling collective action and making it less costly. In the context of natural resources, social norms and social interactions are seen as enforcers of cooperation and conservation by making monitoring and enforcement of social arrangements more feasible. In general, social capital acquisition is presented as a mechanism to decrease transaction costs of coordi- 
nating actions, improve information flows, provide mutual insurance, and serve as informal collateral $[16,17]$.

Other aspects of the migration process that are relevant for the characterization of exit options, which have recently been the subject of research [18], include migrant selectivity; the role of social networks through facilitateing moves, assisting with assimilation in places of destination, and maintaining ties to places of origin; the timing of a move; the distance between origin and destination $[19,20]$, and the type of economic incentives that drive the migrant to move. Including these dimensions of migration in the analysis of migration's effects on places of origin or destination highlights the social nature of this process and its crucial interaction with market mechanisms. In this sense, migration theory and evidence increasingly recognizes the importance of social networks and market incentives for understanding social and environmental collective action outcomes.

\section{External Factors Influencing Availability of Opportunities}

Recent articles mention the importance of incorporating "external" factors to the microeconomic analysis of conservation and cooperation. Agrawal and Gibson [21] suggest extending the local-level analysis to incorporate the context of larger geographical, social, and economic forces (government policies, prices of different resources, development assistance, demographic shifts, technological innovations, institutional arrangements, etc.). Seabright [22] notes that developing countries are moving toward greater clarity and enforceability of laws at the same time that they are moving toward greater reliance on markets.

A main shortcoming of the main studies reviewed so far is their neglect of the scope of market integration in the formation of exit opportunities. Availability of outside opportunities is tightly related to the process of market integration. For example, outside options may be reduced in the presence of missing or incomplete credit, rental, or labor markets. To the contrary, well-functioning markets may enhance access to outside options. For the terai in Nepal, Bluffstone [23] argues that off-farm labor of households allows them to increase their income, switch from firewood to fuels, and reduce their levels of deforestation. At the same time, in regions where labor markets are missing, animal husbandry activities increase, resulting in increased deforestation. Other authors [10] actually calculate the impact of shadow wages (the difference between the opportunity cost of labor and market wages created by market imperfections) on labor supply and the collection of firewood.

Market integration and imperfections can affect the relationship of wealth, value of exit options, and cooperation $[10,23,24]$ by affecting determinants of the value of exit options (e.g., shifts in occupational structure away from traditional agricultural and livestock practices, availability of cleaner substitutes to manure and firewood, etc.) and of the relevance of wealth in order to access these options (e.g., availability of education or employment). Baland et al. [10] link market integration with modernization, commercialization, and agricultural intensification. Increased market integration and commercialization of rural communities can intensify agricultural operation and promote deforestation as more forestland is cleared for agricultural use. Valdivia et al. [25] observe that production strategies pursued by households and individuals in a peasant community of the Bolivian Altiplano are partially shaped by the ability to develop urban rural linkages. In an empirical study of 48 irrigation communities in India, Bardhan [26] finds that the effect of urban connections of the village - to urban areas or to transport and communication modes-has a negative effect on the sustainability of community-level cooperation. The same is the effect of a variable indicating a farmer's orientation toward markets (in terms of sales of produce) and access to alternative irrigation sources outside the group.

An important question deals with how economic integration interacts with local social networks and ultimately influences local collective action outcomes. As noted by many studies in economic development, missing markets produce social capital, but at the same time, social capital can be exclusive. Similarly, economic integration may reduce the opportunity cost of exiting local arrangements, but the access to new opportunities created by economic integration may depend on how broad and inclusive property rights and other institutions are $[27,28]$.

An interesting conceptual framework for the characterization of market integration is provided by Angelsen [29] and Angelsen and Kaimanovitz [30] in their examination of the macroeconomic processes that affect natural resource degradation. They use four models, each one characterized by different levels of market integration, to compare their results. These results may be interpreted as the analysis of heterogeneous agents (across models), facing different external opportunities and constraints. Their four models may also be used to represent different coexisting integration scenarios. For example, for subsistence economies the option of alternative employment does not exist, while in more integrated economies the increment of this option may tend to increase or reduce deforestation (increase cooperation in the interpretation of the CPR literature), depending on the degree of market access (broad or narrow), the type of productive options considered, and the existing social norms and institutions. Such a conceptualization of the problem would allow for different results that are more suited for specific contexts, such as in the case of agricultural intensification (Baland et al. 2006), producing a negative effect on the sustainability of community-level cooperation (Bardhan 2001) 
or, rather, providing an "exit option" to reduce the pressure on deforestation (Bluffstone 1995).

\section{Discussion and Conclusions}

This article examines how outside opportunities have been conceptualized in the CPR management literature, the predictions under alternative frameworks, and the empirical evidence associated with these results. We find that the most commonly used framework of analysis is a micro-level framework, which implies geographical boundaries and treats agents as "highly homogeneous"-having the same or similar opportunity costs of participation (costs of not undertaking alternative economic activities outside the commons) and, consequently, having the same or similar economic options.

We review some of the few studies allowing for heterogeneity in opportunity costs and outside economic options. These studies emphasize differences in opportunity costs across agents, depending on CPR contribution type: monetary versus in terms of time. They also underscore the relationship of opportunity costs with the wealth of an individual and the existence of cost thresholds that determine exit from a collective action situation.

While the heterogeneous opportunity costs are more straightforward to analyze with monetary contributions (there is a direct relationship between the wealth of an individual and the ability to provide monetary payments), time contributions require more complex analysis and depend on time preferences and factors affecting them (such as income and education). Regarding the relationship of opportunity costs with the wealth of an individual, it is found that this can be conceptualized as a function that maps income to the value of exit options which, according to Dayton-Johnson and Bardhan [7], may take a concave or convex shape. Thus, the heterogeneity in opportunity costs may result in the lack of full participation in the provision or management of a good, but may or may not deter a few agents from providing or efficiently managing the resource.

This highly stylized conceptualization provides a useful way to illustrate the broad array of possible collective action results associated with different shapes of the exit option function and with different income inequality scenarios. However, it provides little guidance in terms of the socio-economic contexts in which such different functional forms arise. Higher or lower inequality of opportunities within a group of individuals is not related only to the degree of income inequality. Examining related strains of the economic development literature, we analyze the importance of socio-economic factors, other than income, which help determine the relative value of exit options across agents and also the shape of the relationship between wealth, inequality of opportunity, and exit options.
Beyond income, the relative value of exit options may depend on whether individuals are migrants from other regions, are landless, are interested in extracting the resource for a rapidly growing market, or belong to strong local social networks $[6,15,22,31]$. The shape of the relationship between wealth and exit options depends on the breadth and quality of markets and institutions $[3,27,28]$. If markets (especially insurance and credit) and institutions were perfect, everybody would have the same opportunities, and exit options would not depend on wealth. However, with market and institutional imperfections, it is common to see income having an important effect on the access to opportunities. For example, it will present increasing returns to scale in productive activities that require fixed cost investments or large coordination (e.g., agricultural perishable markets), in markets with high quality standards and high needs for marketing knowledge, in activities that are poorly regulated by regulatory bodies and where monopoly rents exist, and in contexts with imperfect credit markets. These cases can be associated with Dayton-Johnson and Bardhan's convex function type, where the rich have higher incentives to exit a collective action arrangement for local resource management. To the contrary, the concave case, where the poor have more incentives to exit, may be associated with difficulty in doing longer-term investments and having weak ties to the local space and social networks.

Finally, the standard characterization of exit options is problematic to the extent that these are defined in terms of the functional nature of a common pool resource, where little recognition is made of the effects of markets, of the social position of individuals over life-courses, and of contending and complementary concerns with conservation. This article underscores the important role that markets play in the formation of exit opportunities, and thereby, collective action and natural resource conservation. It also shows how the results of a "closed" microeconomic framework analysis which imposes geographic, group, or community boundaries, and places where outside opportunities are considered as options to "exit" cooperationthus, leading to depletion of resources and reductions in welfare-can stand in contraposition with conclusions resulting from a wider perspective, where outside opportunities include other welfare improving components and reduce the need to deplete resources. Participatory approaches defined in terms of the functional nature of a common pool resource thus might narrow the view of research concerned with welfare.

\section{REFERENCES}

[1] M. Olson, "The Logic of Collective Action," Harvard University Press, Cambridge, 1965.

[2] R. Benabou, "Inequality and Growth," NBER Macroee- 
conomics Annual, Vol. 11, 1996, pp. 11-74. http://dx.doi.org/10.2307/3585187

[3] A. Shanmugaratnam, T. Velded, A. Mossige and M. Bovin, "Resource Management and Pastoral Institution Building in the West Africa Sahel,” World Bank Discussion Paper, Africa Technical Department Series 175, World Bank, Washington DC, 1992.

[4] R. Johnson and G. Libecap, "Contracting Problems and Regulation: The Case of the Fishery,” The American Economic Review, Vol. 72, No. 5, 1982, pp. 1005-1022.

[5] J.-P. Laurent, P. Mathieu and M. Totté, "Migrations et Access a la terre au Burkina Fasso,” Issue 20 of Cahiers du CIDEP, CIDEP, Paris, 1994.

[6] A. Bergeret and J. C. Ribot, "L'abre Nourricier en Pays Sahelien,” Editions de la Maison des Sciences de l'homme, Paris, 2001.

[7] J. Dayton-Johnson and P. Bardhan, "Inequality and Conservation on the Local Commons: A Theoretic al Exercise,” Economic Journal, Vol. 112, No. 481, 2002, pp. 577-602. http://dx.doi.org/10.1111/1468-0297.00731

[8] J. M. Baland and J. P. Platteau, "Wealth Inequality and Efficiency in the Commons, Part I: The Unregulated Case," Oxford Economic Papers, Vol. 49, No. 4, 1997, pp. 451-482. http://dx.doi.org/10.1093/oxfordjournals.oep.a028620

[9] J. M. Baland and J. P. Platteau, "The Ambiguous Impact of Inequality on Local Resource Management," World Development, Vol. 27, No. 5, 1999, pp. 773-788. http://dx.doi.org/10.1016/S0305-750X(99)00026-1

[10] J. M. Baland, P. Bardhan, S. Das, D. Mookherjee and R. Sarkar, "Inequality, Collective Action, and the Environment: Evidence from Firewood Collection in Nepal,” In: J. M. Baland, P. Bardhan and S. Bowles, Eds., Inequality, Cooperation, and Environmental Sustainability, Chapter 10, Princeton University Press, 2006.

[11] E. Ostrom and R. Gardner, "Coping with Asymmetries in the Commons: Self-Governing Irrigation Systems Can Work," Journal of Economic Perspectives, Vol. 7, No. 4, 1993, pp. 93-112. http://dx.doi.org/10.1257/jep.7.4.93

[12] P. Dasgupta, "Poverty, Population and Natural Resources,” In: Selected Papers of Partha Dasgupta, Vol. 2, Oxford University Press, Oxford, 2010.

[13] K. Weinberger and J. Juetting, "Women's Participation in Local Organizations: Conditions and Constraints," World Development, Vol. 29, No. 8, 2002, pp. 1391-1404. http://dx.doi.org/10.1016/S0305-750X(01)00049-3

[14] S. Engel, M. Iskandarani and P. Useche, "Improved Water Supply in the Ghanaian Volta Basin: Who Uses It and Who Participates in Community Decision-Making? EPT Discussion, International Food Policy Research Institute (IFPRI), Washington DC, 2005, p. 129.

[15] F. J. Pichon, “Colonist Land-Allocation Decisions, Land Use, and Deforestation in the Ecuadorian Amazon Frontier," Economic Development and Cultural Change, Vol. 45, No. 4, 1997, pp. 707-744.

[16] M. Fachamps and B. Minten, "Returns to Social Network Capital among Traders," Oxford Economic Papers, Vol. 54, No. 2, 2013, pp. 173-206. http://dx.doi.org/10.1093/oep/54.2.173

[17] J. Maluccio, L. Haddad and J. May, "Social Capital and Household Welfare in South Africa, 1993-98," Journal of Development Studies, Vol. 36, No. 6, 2000, pp. 54-81. http://dx.doi.org/10.1080/00220380008422654

[18] S. R. Curran, "Migration, Social Capital, and the Environment: Considering Migrant Selectivity and Networks in Relation to Coastal Ecosystems," In: W. Lutz, A. Prskawetz and W. Sanderson, Eds., Population and Environment: Methods of Analysis, Population and Development Review, Vol. 28, 2002, pp. 89-125.

[19] A. Portes, "Transnational Communities: Their Emergence and Significance in the Contemporary World-System," In: R. P. Korzeniewicz and W. C. Smith, Eds., Latin America in The World-Economy, Greenwood Press, Westport, 1996, pp. 151-168.

[20] A. Portes and J. Sensenbrenner, "Embeddedness and Immigration: Notes on the Social Determinants of Economic Action,” American Journal of Sociology, Vol. 98, 1993, pp. 1320-1350. http://dx.doi.org/10.1086/230191

[21] A. Agarwal and C. Gibson, "Enchantment and Disenchantment: The Role of Community in Natural Resource Conservation,” World Development, Vol. 27, No. 4, 1999, pp. 629-649. http://dx.doi.org/10.1016/S0305-750X(98)00161-2

[22] P. Seabright, "Managing Local Commons: Theoretical Issues in Incentive Design,” Journal of Economic Perspectives, Vol. 17, No. 4, 1993, pp. 113-134. http://dx.doi.org/10.1257/jep.7.4.113

[23] R. Bluffstone, “The Effect of Labor Market Performance on Deforestation in Developing Countries under Open Access: An Example from Rural Nepal," Journal of Environmental Economics and Management, Vol. 29, No. 1, 1995, pp. 42-63. http://dx.doi.org/10.1006/jeem.1995.1030

[24] World Bank, "World Development Report 2006: Equity and Development,” World Bank, Washington DC, 2005.

[25] C. Valdivia, C. Jett, R. Quiroz, J. Gilles and S. Materer, "Peasant Household Strategies in the Andes and Potentials Users of Climate Forecasts," Selected Paper, American Agricultural Economics Association Conference, Tampa, 2000.

[26] P. Bardhan, "Irrigation and Cooperation: An Empirical Analysis of 48 Irrigation Communities in South India," Economic Development and Cultural Change, Vol. 48, No. 4, 2000, pp. 847-65. http://dx.doi.org/10.1086/452480

[27] D. Acemoglu, S. Johnson and J. A. Robinson, "Reversal of Fortune: Geography and Institutions in the Making of the Modern World Income Distribution," Quarterly Journal of Economics, Vol. 117, No. 4, 2002, pp. 1231-1294. http://dx.doi.org/10.1162/003355302320935025

[28] S. Engerman and K. Sokoloff, "Factor Endowments, Inequality, and Paths of Development among New World Economies,” Economía, Vol. 3, No. 1, 2002, pp. 41-88. http://dx.doi.org/10.1353/eco.2002.0013

[29] A. Angelsen, “Agricultural Expansion and Deforestation: 
Modeling the Impact of Population, Market Forces, and Property Rights,” Journal of Development Economics, Vol. 58, No. 1, 1999, pp. 185-218.

http://dx.doi.org/10.1016/S0304-3878(98)00108-4

[30] A. Angelsen and D. Kaimanovitz, "When Does Technological Change in Agriculture Promote Deforestation?” In: D. R. Lee and C. B. Barrett, Eds., Tradeoffs or Synergies?
Agricultural Intensification, Economic Development, and the Environment, CABI Publishing, New York, 2001, p. 89. http://dx.doi.org/10.1079/9780851994352.0089

[31] E. Ostrom, "Collective Action and the Evolution of Social Norms,” Journal of Economic Perspectives, Vol. 14, No. 3, 2000, pp. 137-158.

http://dx.doi.org/10.1257/jep.14.3.137 